\title{
POR UMA METAFÍSICA DE TRAMAS O MUNDO SEM ARCHÉ
}

\author{
Hilan Bensusan* \\ hilantra@gmail.com \\ Tomás Ribeiro Cardoso** \\ tomasrcardoso@gmail.com
}

RESUMO Este trabalho apresenta a distinção entre metafísicas de paisagens e metafísicas de tramas. De acordo com as primeiras, o esforço metafísico deve ser ocupar um ponto de vista privilegiado exterior de onde possamos apresentar uma paisagem completa e final das coisas. De acordo com as últimas, o esforço metafísico deve ser explorar as tramas produzidas pela composição de diferentes paisagens desde seu interior. O trabalho defende as últimas mostrando que elas podem responder (pelo menos parcialmente) às inquietações que movem as suspeitas acerca de empreitadas metafísicas em geral. O trabalho procede ilustrando o conceito de metafisica de tramas por meio do esboço de um realismo quanto à indexicalidade, às disposições e às perspectivas.

Palavras-chave Metafisica,trama,paisagem,disposições, indexicalidade, perspectivas

ABSTRACT This work draws a distinction between a metaphysics of landscapes and a metaphysics of plots. According to the former, the metaphysical endeavor aims to achieve a privileged external perspective with which we could come up with a complete and finished image of the world.

* Professor Adjunto do Departamento de Filosofia da UnB. ** Mestre pelo Departamento de Filosofia da UnB. Artigo recebido em 27/11/2010 e aceito em 11/6/2011.

KRITERION, Belo Horizonte, $n^{\circ}$ 125, Jun./2012, p. 281-298. 
According to the latter, the metaphysical endeavor aims to explore from within the plot produced by the joint implementation of different landscapes. The work puts forward and favors the latter showing that they have resources to (at least partially) face the worries that trigger the unease towards metaphysical endeavors in general. The last part of the work illustrates the concept of metaphysics of plots by putting forward a sketch of a realist stance towards indexicals, dispositions and perspectives.

Keywords Metaphysics, plot, landscape, dispositions, indexicality, perspectives

\section{A metafísica de paisagem}

A história (oficial) da ontologia no ocidente parece ser uma história de uma busca por uma imagem final - uma imagem total, capaz de englobar tudo e que se pareça com uma lista de ingredientes para qualquer receita. Trata-se de uma imagem de uma tabela periódica, uma tabela onde têm lugar objetos, substâncias, propriedades, eventos, estados, fatos e coisas que tais. O esforço parece ser o de apresentar os componentes de uma imagem. Uma imagem: ser é ser passível de contemplação de algum ponto de vista privilegiado. Ser é ser parte de uma paisagem que poderia ser vista de alguma parte.

A metafísica deveria, então, apontar para uma paisagem que, em princípio, poderia ser visível desde algum ponto de vista especial; e sua tarefa é a de proporcionar um vislumbre desta perspectiva (que torna inadequada ou parcial qualquer outra perspectiva). A metafísica é assim entendida como a empreitada de, uma vez alcançado o ponto adequado para a contemplação, inventariar o que há no mundo, apresentando uma ontologia. ${ }^{1}$ Haveria, desse modo, uma paisagem original, alheia a toda interação que temos com ela e, de modo mais geral, alheia a qualquer trama que algum dos componentes suscita, impele ou propicia sobre qualquer outro.

O pensamento em metafísica se orientou pela busca de uma ordem por trás do caos. Talvez por isso a preocupação ontológica se concentrou em buscar categorias e classes de entes. A filosofia do que existe tem seu foco em um esforço de almoxarife: uma tipologia das coisas. Estes tipos últimos são a base, o fundamento das coisas - uma suposta arché - que rege pelo menos

1 Tal inventário seria o que em geral chamamos de ontologia. Ou seja, trataremos a ontologia como parte da metafísica: aquela que trata diretamente do que há. 
as coisas naturais. ${ }^{2} \mathrm{~A}$ imagem da paisagem, desse modo, se associa a imagem da realidade última, da paisagem na qual todas as demais paisagens colapsam. Trata-se de uma imagem desprovida de qualquer interferência de qualquer outra parte da imagem.

É certo que a imagem foi objeto de todo tipo de críticas endereçadas à possibilidade mesma de qualquer conhecimento metafísico. Como seria possível ascender a este ponto de vista privilegiado que permite ver as coisas com independência dos nossos hábitos, da constituição das nossas condições para a experiência, das nossas predisposições e das nossas capacidades conceituais? Alguns argumentos, em grande medida tributários das suspeitas de Hume, tentaram estabelecer que toda imagem do mundo que sejamos capazes de apresentar não é mais do que uma correlação entre nós e as coisas. Uma visão de um olho universal posicionado em parte alguma não pode ser alcançada e, se é assim, não há a possibilidade de um conhecimento metafísico (ou nem sequer de termos crenças metafísicas verdadeiras). Uma vez que o conhecimento metafísico não pode ser outra coisa senão uma paisagem contemplada de um sítio neutro, ele fica parecendo inatingível. Porém, ainda assim, a imagem (da paisagem) persiste como a imagem de uma impossibilidade.

Podemos diagnosticar um dilema com respeito às suspeitas acerca do conhecimento metafísico. Ou a metafísica é uma empreitada possível já que podemos alcançar (ou vislumbrar) um ponto de vista em que as coisas possam estar dissociadas da correlação que elas tenham com as outras (e conosco), ou tal ponto de vista é inalcançável e não podemos mais do que tratar da correlação entre nós e as coisas. Ou seja, ou podemos alcançar a perspectiva neutra através da qual vemos as coisas mesmas com independência de nossa interferência nelas ou nos conformamos com nossas próprias perspectivas sobre as coisas (como uma solução de segunda categoria, já que a perspectiva que importa não pode ser alcançada). Diante deste dilema, muitas vezes nos encontramos em um movimento pendular análogo àqueles que McDowell tornou populares (1994). Sentimos, por um lado, a atração de buscar uma paisagem sem interferência, de uma arché do mundo que seja independente de nossas capacidades e sentimos, por outro lado, a atração de uma suspeita de que tudo o que pensamos está permeado de um elemento que é, em algum sentido, irremediavelmente nosso. 
Esse par de atrações promove um movimento pendular. Este movimento provoca diferentes respostas em filosofia. Começaremos mencionando apenas duas. Podemos, por exemplo, adotar certos realismos locais conjugados a uma imagem global do conhecimento que implique que não podemos senão conhecer as coisas tais como elas aparecem para nós. Ou seja, podemos ter atitudes realistas que atendem a um pólo de atração associadas a uma atitude geral kantiana que atende ao pólo oposto de atração. A segunda resposta é, como no caso dos pêndulos de McDowell, enfrentar o perigo de uma oscilação permanente. Na primeira resposta tentamos conciliar os dois polos; na segunda, assumimos que eles são inconciliáveis.

Uma outra resposta possível é considerar um ponto de vista que pareça mais tangível. Caso a paisagem de um ponto de vista de parte alguma ${ }^{3}$ seja inacessível, resta-nos a paisagem de um ponto de vista que seja, em algum sentido, nosso. Trata-se não de um ponto de vista de uma só pessoa ou de um bando, mas de um ponto de vista que carregue consigo certa universalidade e alguma corrigibilidade (pois se pode fazer a distinção entre o que parece e o que é de fato visível desse ponto de vista). Kant explorou essa possibilidade considerando que podemos ter uma maneira de conceber as coisas ditadas por um sujeito transcendental que transfere a seus fenômenos uma universalidade e uma necessidade. O recuo é de uma paisagem vista de parte alguma rumo a uma paisagem vista por nós, onde o nós, de algum modo fora da paisagem, ganha contornos e critérios de identificação estáveis. No entanto, pode haver suspeitas de que possamos conceber um nós fora da paisagem, fora daquilo que está acessível ao nosso ponto de vista - nosso suposto conhecimento, mesmo que dos fenômenos. Neste caso, o nosso ponto de vista pode parecer o ponto de vista em que nós nos colocamos em parte alguma, em uma espécie de mirante estrangeiro à paisagem contemplada. O nós é assim colocado fora da paisagem (paisagem para nós) e, portanto, teremos que ter dele um conhecimento metafísico, do tipo que se tentou exorcizar. ${ }^{4}$ Ou seja, o nós não pode ser um nós-para-nós, ele não pode ser visto do nosso ponto de vista, mas antes de um ponto de vista de parte alguma. Se quisermos mais do que um nós para nós ${ }^{5}$ o nós tem que ser conhecido desde fora de nós já que o nosso ponto de vista não pode senão contemplar paisagens de interações entre nós

3 A expressão provêm de Th. Nagel, A View from Nowhere (1986).

4 Ver uma discussão assemelhada em Heil \& Martin (1999). No texto, os autores argumentam pela inevitabilidade da ontologia. Mesmo os idealismos e anti-realismos têm ontologias subjacentes, algumas das quais menos plausíveis que outras.

5 Seja o que for que seja um nós para nós, os riscos aqui são que percamos a corrigibilidade: aquilo que pareça visível do ponto de vista que estamos (que parece que estamos) é aquilo que é visível. 
e o mundo. O nosso ponto de vista só pode ser um ponto de vista estável se pudermos ter algum conhecimento do nós - por exemplo, de sua extensão. Tal conhecimento do nós estaria sujeito às mesmas críticas que assolam as pretenções de conhecimento metafiśico entendido como um acesso a uma paisagem vista de parte alguma. ${ }^{6}$

A ideia de uma paisagem vista de parte alguma a ser desvelada supõe uma diferença original (ou final) entre quem vê e o que é visto. Tal diferença original inaugura o que queremos chamar de metafísica de paisagem. E esta ideia é parte tanto da busca metafísica por uma visão de parte alguma quanto da crítica a essa busca, que procura substituir as pretensões da metafísica por uma doutrina do mundo para nós. No primeiro caso há uma paisagem vista de parte alguma de onde se pode determinar como são as coisas. No segundo caso, há uma paisagem vista por um nós que está fora da paisagem e fixo. Ou seja, os dois lados do dilema são reféns da metafísica de paisagem: ou há um ponto de vista de parte alguma - e a crítica ao conhecimento metafísico advoga que tal ponto não pode ser alcançado - ou temos que apostar em um ponto de vista nosso. Em ambos os casos, é suposta uma paisagem contemplada de alguma parte privilegiada.

Se pudermos exorcizar tal metafísica, poderemos fazer repousar o movimento pendular. Gostaríamos de explorar aqui a possibilidade de uma metafísica que não comece e nem termine com a concepção de uma paisagem e de um ponto de vista privilegiado.

\section{A metafísica de tramas: planos, improvisos e implementações}

Uma metafísica de paisagem é aquela em que o mundo pode ser capturado por uma lista de elementos (finita ou infinita) que o compõem. A ideia de paisagem encoraja a tese de que há um mobiliário fixo do mundo, seja visto por nós seja visto de alguma parte. Recusar a ideia de que há uma paisagem subjacente ao mundo significa que toda metafísica deve ser feita não desde fora, mas sempre dentro de uma paisagem. Uma metafísica que recuse a noção de paisagem abandona a ideia (de almoxarifado) de que o exercício metafísico

6 Comparar com Nietzsche (1886/2008), parte 2, seção 61. Nietzsche considera a metafísica de nós segundo a qual há naquilo que chamamos de nós uma vontade emancipada. Ele diz, o medo do destino também faz parte do destino, assim como a resignação diante dele. Nietzsche tem em foco aqui contra ideia expressa, por exemplo, no trecho do Talmud Babilônico (Berachot 33b) onde se lê que "[...] tudo depende do céu menos o temor ao céu". Ou seja, para Nietzsche, também o temor ao céu (ou ao destino) depende do céu (ou do destino). Para defender a resignação diante do desitno como uma expressão da vontade emancipada - ou o caráter especial de um ponto de vista por ele ser nosso - teríamos que motivar estas exceções ao fatalismo e a suspeita acerca do conhecimento das coisas mesmas. 
é (apenas) aquele de apresentar uma lista de dramatis personae do mundo. Ou seja, que personagens permanentes são suficientes para determinar todas as tramas que têm lugar no mundo. Em contraposição a uma metafísica da paisagem, nós queremos propor e esboçar uma metafísica de tramas, segundo a qual nenhuma lista de almoxarifado, nenhuma paisagem, torna dispensável o apelo às tramas que têm lugar com a interação das personagens. De fato, e isto ficará mais claro em seguida, se uma metafísica de paisagem é uma peça que designa um papel a ser desempenhado por cada personagem, uma metafísica das tramas é um espaço de improvisação. A improvisação que se segue de que cada personagem pode esbarrar em outras tramas.

Podemos começar a entender o que está em jogo na possibilidade de uma ontologia das tramas evocando a distinção de Deleuze e Guattari entre plano de imanência e plano de transcendência. Trata-se de uma distinção entre planos que é também uma distinção entre dois sentidos de 'plano'. Um plano pode ser um projeto, um princípio oculto,

que dá a ver aquilo que se vê, a ouvir aquilo que se ouve..., etc., que faz a cada instante que o dado seja dado, sob tal estado, a tal momento. Mas ele próprio, o plano, não é dado. Ele é oculto por natureza. Só se pode inferi-lo, induzi-lo, concluílo a partir daquilo que ele dá (simultaneamente ou sucessivamente, em sincronia ou diacronia). [...] É um plano de transcendência. (1980/2007, v. 4, p. 54).

O plano de transcendência é como uma paisagem subjacente ao que é dado, como uma partitura que não se ouve na música ou um edital que não é ele mesmo parte da prova de um concurso. Trata-se de um plano enquanto organograma, roteiro, conjunto de instruções. E há um outro plano, um outro sentido de plano, chamado de plano de composição e que é

um plano de imanência e de univocidade. [...] por mais que cresça em dimensões, ele jamais tem uma dimensão suplementar àquilo que se passa nele. [...] É, portanto, um plano de proliferação, de povoamento, de contágio; mas esta proliferação nada tem a ver com uma evolução, com o desenvolvimento de uma forma ou a filiação de formas. É menos ainda uma regressão que remontaria a um princípio. É, ao contrário, uma involução, onde a forma não para de ser dissolvida para liberar tempos e velocidades. (1980/2007,v. 4, p. 55-6)

O plano de imanência é onde os acontecimentos precisam estar - nele há a univocidade dos acontecimentos, eles estão no mesmo pé. É nele que as organizações têm lugar, elas precisam ter lugar neste plano para que elas se dêem, para que delas algo aconteça. O plano de imanência não é um ponto de vista a ser ocupado, é antes o espaço onde as ocupações têm lugar. Não é o projeto do acontecimento, é o plano onde têm lugar os acontecimentos. 
Queremos fazer uso desta distinção entre o plano de organização e o plano de imanência (onde ocorre a implementação da organização) da seguinte maneira. $\mathrm{O}$ plano de transcendência inaugura uma paisagem e um ponto de vista sobre o mundo - como a partitura inaugura o que há para ser executado na música. Em uma metafísica de paisagem, não há mais do que um plano de transcendência, isto é, um ponto de vista exclusivo a partir do qual tudo pode ser contemplado. A execução da organização planejada apenas cumpre o plano já que as tramas não são mais do que consequências das personagens. Uma metafísica de tramas, em contraste, entende que o plano de implementação é um plano comum a mais de um plano de organização, ele é o plano de imanência. Porque o plano de imanência é o plano de implementação de toda e qualquer paisagem, ele não é uma paisagem - ele é um plano em um sentido inteiramente diferente. O plano de imanência é o plano das tramas. Segundo uma metafísica de tramas há sempre mais de um plano (de organização) sendo implementado no plano comum das tramas. Ou seja, um plano de organização isolado falha (ou pode falhar) porque ele compartilha um plano de imanência com outros planos e, assim, cada plano afeta os demais.

Segundo uma metafísica de tramas não há nenhum habitante que, introduzido em um plano (de organização), torne este plano o único plano (de organização). A mera introdução de qualquer habitante no plano de organização não é capaz de tornar considerações sobre a implementação irrelevantes. Nenhum elemento, por mais complexidade que introduza, poderá dar conta da co-extensão planos (de organização). Podemos enunciar a tese substancial de uma metafísica de tramas (que chamaremos de TMT) da seguinte maneira: há um plano de imanência. Este plano, só um, não pode ser reduzido a nenhum conjunto de planos de organização. Se introduzimos o plano de imanência, introduzimos a insuficiência das personagens, e das paisagens, já que a implementação do plano (de organização) faz com que elas não bastem já que elas dividem o mesmo plano de imanência com outros projetos, com outras organizações.

Uma metafísica de tramas atenta para o que os movimentos das personagens produzem em alianças com outras personagens igualmente presentes - já que o palco é palco de mais de um roteiro. Se esses movimentos forem inventariados, as tramas são reduzidas a paisagens. TMT é a tese segundo a qual tal redução não pode se dar já que a implementação mesma de qualquer roteiro requer um palco onde outras coisas estão sendo implementadas. Há sempre a madeira do palco se decompondo, o barulho da rua, os organismos que pairam pelo ar em torno dos atores. TMT é uma tese acerca da irredução: as tramas não podem ser reduzidas a paisagens, não basta apresentar o mobiliário do universo. 
A ideia de uma metafísica de tramas advém de uma tentativa de exorcizar o dilema em que a crítica ao conhecimento metafísico nos coloca: entre prosseguir buscando paisagens de parte alguma ou nos contentar com alguma paisagem vista por nós. Trata-se de uma metafísica no sentido de se ocupar com o que há, não a partir da busca de uma paisagem, mas do desvelamento de tramas que ocorrem em todos os âmbitos e que se dão em um mesmo plano. Não há como descrever o plano senão pelo que ocorre nele - trata-se de um plano de acontecimentos. Neste sentido, não há uma ontologia subjacente às tramas, a implementação das tramas é tudo o que constitui algo que pode ser considerado como o mobiliário último do universo. Assim, não há uma metafísica da contemplação de uma paisagem, mas antes um envolvimento em uma teia de tramas. Este é o sentido de TMT, exorcizar a metafísica da sedução da paisagem.

Ideias relacionadas com a metafísica das tramas podem ser também encontrada em muitos momentos da história da filosofia ocidental. Algo dela está talvez presente na noção de polemos de Heráclito ${ }^{7}$, que fazia da polêmica um elemento central de como são as coisas. Os esforços para trazer a tona uma concepção do mundo baseada em forças e devires, como tentou fazer Nietzsche, também indicam elementos em que o mundo é pensado não em termos de personagens, mas antes em termos de atores e suas performances. ${ }^{8}$ Ao longo do século XX e, sobretudo, na virada para o século XXI podemos encontrar elementos que apontam para uma metafísica de tramas, em trabalhos como os de Whitehead (1929), Bergson (1907/2007), Souriau (1943/2009), Deleuze e Guattari (1980/2007), Latour (1987), Cantwell Smith (1996), Kit Fine (2005) e em geral em torno dos debates recentes acerca do realismo especulativo (Harman 2009, por exemplo). TMT, de certa maneira, explicita o que parece estar em questão em todos estes esforços.

Esboçamos, a seguir, algumas teses metafísicas que se coadunam e que nós consideramos bastante encorajadas por TMT. Não queremos dizer, contudo, mais do que o seguinte: as teses que apresentaremos compõem uma entre um indeterminado número de metafísicas de tramas possivelmente incompatíveis entre si.

7 Vale notar que na metafísica de tramas, a política se confunde com a metafísica, já que não há um elemento alheio a disputas, alianças e influências. A política fica dentro da metafísica. Na verdade, a metafísica de tramas não permite que se diga nem que a metafísica precede a política e nem o seu contrário - não há ordem de precedência global.

8 Cf em particular Haar (1993) onde Nietzsche é apresentado como um transformador da metafísica. 


\section{A indexicalidade no mundo}

Uma diferença crucial entre a metafísica de paisagens e a metafísica de tramas diz respeito à indexicalidade. Uma maneira de começar a considerar se há elementos indexicais no mundo é invocar a distinção de McTaggart (1908) entre duas componentes do tempo, que ele denomina de série A e de série B. A série B é a série formada por datas ordenadas em uma série regular não-indexical, como a série dos anos, dos dias ou das horas, tal como aparece nos calendários (...2010, 2011, 2012...). A série B é ordenada desde um ponto de vista que não está em parte alguma da série. A série A, por sua vez, é composta de momentos ordenados de acordo com uma posição dentro da própria série (...ano passado, este ano, ano que vem...). Ou seja, os momentos no tempo de acordo com a série A são sempre relativos a uma posição no tempo. A série B não oferece uma noção de passado, presente e futuro - é como se as componentes da série estivessem dispostos em uma ordem que não indicam a passagem do tempo. $\mathrm{Na}$ série B, segundo McTaggart, nada se passa porque a ideia de mudança requer que um presente tenha se tornado passado, requer recursos que apenas a série $\mathrm{A}$ pode prover. McTaggart argumenta que a série A parece implicar que o mesmo fato pode ser passado, presente e futuro de acordo com alguma perspectiva temporal. Ele considera que a série A é ao mesmo tempo essencial ao tempo e à mudança e tem consequências intoleráveis já que os eventos do mundo, por exemplo, teriam que ser sempre tomados como eventos passados, presentes ou futuros em relação a um referencial - a um tempo presente em particular. McTaggart entende que qualquer escolha de um referencial temporal em particular é arbitrária já que será relativa, pelo menos, à posição do observador no tempo. Por essa razão, ele defende a irrealidade do tempo. Vale notar que esta tese se segue da conexão que ele via entre o tempo e a série A; se ele aderisse ao que muitas vezes se chama de B-ismo, a tese de que o tempo não requer a série A, não haveria nada que impelisse McTaggart a rejeitar a realidade do tempo.

A posição de McTaggart é exemplar com respeito à metafísica de paisagem. Ele recusa a realidade do tempo porque, tendo a série A como componente essencial, somos obrigados a aderir a três teses sobre a realidade que, juntas, conflitam com as intuições constitutivas de (pelo menos a maior parte das) metafísicas de paisagem: a realidade deve ser neutra (deprovida de uma perspectiva privilegiada), absoluta (desprovida de mais de uma perspectiva) e coerente (sem contradições). Vale a pena considerar um pouco estas três teses.

Segundo a primeira tese, a realidade deve ser neutra no sentido de ser a mesma vista de qualquer parte (e também por qualquer um, em qualquer estado etc.). É uma paisagem de parte alguma e, portanto, não pode haver 
um ponto de vista privilegiado quando se trata de inspecionar a realidade ainda que haja pontos de vista (por exemplo, o da lente de um microscópio potente) que nos ajudem a ver a realidade que poderia ser vista independente de qualquer perspectiva (por alguém, em princípio). Um versão de A-ismo (que ao contrário do B-ismo entende que a série A é imprescindível ao tempo) toma o tempo presente como um tempo privilegiado - o presentismo. $\mathrm{O}$ presentismo é um A-ismo que preserva o caráter absoluto e o caráter coerente da realidade abrindo mão de uma perspectiva de parte alguma em favor de uma perspectiva presente.

Segundo a segunda tese, a realidade deve ser absoluta, ela não pode ser ela mesma indexada, aquilo que é real não pode ser apenas real-parauma-perspectiva. O A-ismo que nega a tese da realidade absoluta defende que há uma relatividade interna ao mundo. Trata-se de um perspectivismo ou um realismo quanto a perspectivas já que o mundo ele mesmo é feito de perspectivas - elas não são inseridas desde fora mas são inerentes a ele.

Segundo a terceira tese, a realidade é coerente. Ou seja, há um requisito de consistência a ser obedecido por tudo o que é real. O presentismo e o perspectivismo aderem a essa tese. Kit Fine (2005) analisa as alternativas que se abrem ao A-ismo e abraça uma forma de A-ismo que rejeita a coerência da realidade e que ele denomina de fragmentalismo. $O$ fragmentalismo sustenta, com o perspectivismo, que há perspectivas imanentes à realidade e, com o presentismo, que a realidade é ela mesma absoluta. A manobra é de postular uma über-realidade que conjuga as realidades indexadas por todas as perspectivas e que, ela mesma, não é coerente (ainda que as realidades indexadas o sejam). Esta über-realidade não é uma visão de parte alguma, mas antes um aglomerado de perspectivas que podem incluir eventos como "estou sentado" e "estou de pé" uma vez que as indexações temporais desaparecem. Como sempre estou observando as coisas desde dentro de alguma perspectiva, sou coerente; mas a über-realidade ela mesma não é. Ela é neutra e absoluta, mas não é uma perspectiva nem uma paisagem. Em comum com o perspectivismo, o fragmentalismo mantém que a realidade contém perspectivas e que não pode ser observada como uma paisagem. O fragmentalismo, contudo, retém um elemento de metafísica de paisagem: há uma über-realidade que reúne as perspectivas, porém ela as engloba sem as suprimir. Ela não é como uma unterrealidade feita do conteúdo puro das diferentes perspectivas (e assim delas

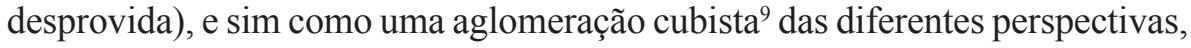


cada uma amontoada sobre as demais. Não se trata de algo que possa ser visto, mas apenas concebido por um exercício de aglutinação de perspectivas.

Kit Fine procura estender o fragmentalismo para outros domínios onde a indexação por perspectivas pareça se impor. ${ }^{10}$ Contra a neutralidade, posições como a de David Lewis (1986) consideram que os mundos possíveis, incluindo o atual estão em pé de igualdade. São posições de realismo neutro, que podem ser fragmentalistas ou perspectivistas - e como tal, podem ser defendida com base na suspeita de que há uma medida de chauvinismo em abandonar a tese da neutralidade da realidade e em adotar uma perspectiva privilegiada. No caso do realismo modal de Lewis, por exemplo, dizer que o mundo atual é um mundo possível entre outros e que não tem nada de substancial que o distinga significa dizer que a atualidade é indexical - ser o mundo atual é ser este mundo. A atualidade não é nada senão uma posição em relação aos outros mundos possíveis e a nós, que estamos em um mundo possível em particular. Ser atual não é uma propriedade que possa ser contemplada como uma paisagem, mas um indexical que diz respeito a posições particulares e a interações a partir delas.

TMT ela mesma parece evocar uma dimensão de indexicalidade: as tramas se dão em interrelações. A mera presença de sangue quente no corpo de um cavalo atrai o bote do carrapato de Uexkull ${ }^{11}$, já que o cavalo passava ali por perto do galho onde estava o carrapato e seu sangue estava em uma termperatura maior do que o ponto de referência. Porém a trama não se reduz a paisagens já que o cavalo tem uma origem particular e um destino (ele pode estar fugindo de um dono que quer higienizar completamente sua pele) que vão agora afetar a vida do carrapato. A trama do carrapato, e a do cavalo, acontecem no mesmo plano de implementações - este plano não é cartografado a partir de uma visão de parte alguma, mas é feito de indexicais, proximidades relativas, intensidades comparativas. Incidentalmente, é interessante notar que a série B está conectada com o plano de organização, com a ordenação indiferente aos acontecimentos no plano comum das implementações.

A indexicalidade intrínseca - e as formas de A-ismo que dela decorrem - pode esclarecer um pouco mais a espécie de metafisica de paisagem que decorre do esforço (kantiano e pós-kantiano) de tratar apenas das coisas para nós motivado pelas críticas à possibilidade de conhecimento metafísico. Kit Fine favorece os A-ismos que mantêm a tese da neutralidade (perspectivismo,

10 A extensão do drama de McTaggart foi aventada diversas vezes ao longo do século XX. Interessante considerar o esforço de Prior (1968).

11 Cf. Uexküll \& Kriszat (1934). 
fragmentalismo) contra aqueles que a abandonam (por exemplo, o presentismo). Chamemos estes últimos de A-ismos não-neutros. Uma posição como a de Kant é uma posição que, diante do caráter perspectival das coisas, prefere rejeitar a neutralidade para garantir o caráter absoluto e coerente da realidade - um A-ismo não-neutro. A perspectiva supostamente estável do nós é uma perspectiva privilegiada que não confere realidade a nenhuma outra. Há apenas uma perspectiva - que contempla o mundo como uma paisagem - e as coisas vistas a partir dela. Assim como o presentismo, as outras formas de A-ismo não-neutro precisam motivar a tese de que uma perspectiva merece ser escolhida em detrimento das demais. O A-ismo não-neutro é uma forma de metafísica de paisagem já que apenas uma perspectiva oferece o ponto de vista que permite contemplar aquilo que há (para esta perspectiva). As alternativas de A-ismo neutro, por outro lado, consideram que há uma multiplicidade de perspectivas associadas à indexicalidade, já que as coisas são coisas-para-nós para algum nós, nenhuma das quais mais real que nenhuma outra.

\section{Disposicionalidade no mundo}

TMT parece também encorajar uma metafísica que não seja atualista. Ou seja, uma metafísica onde haja alguma coisa como possibilia, conexões disposicionais entre eventos, potências e capacidades. O tema é amplo e merece atenção maior do que o escopo dessa seção, portanto nos limitaremos a indicar alguns elementos em que os não-atualismos apontam em direções convergentes com as metafísicas de tramas concentrando nosso foco em disposições.

Diferentes maneiras de entender as disposições têm sido propostas (Martin 1994, Mumford 1998, Ellis 2002). Uma delas nos parece bastante interessante do ponto de vista de uma metafísica de tramas em sua relação com perspectivas e indexicalidade. Molnar (2003) propõe que tomemos disposições como sendo casos primitivos de intencionalidade que ele chama de intencionalidade física. Molnar toma as quatro características que Brentano associa à intencionalidade e procura mostrar que ela é a marca do disposicional e não (apenas) do que é mental, como queria Brentano. As quatro características são as seguintes:

a) Direcionalidade. Algo intenciona (alguma coisa) quando de algum modo está dirigido ou direcionado a algo diferente de si mesmo. Assim, acreditamos que a terra é redonda, desejamos um copo d'água. Analogamente, a solubilidade em um sal está direcionada à água - é como se uma parte do mundo se direcionasse à outra e, assim, a pressupusesse ou a postulasse. 
b) Direcionalidade ao que não existe. Algo pode intencionar o que não existe, como quando alguém acredita em pégaso ou em flogisto ou deseja uma montanha de ouro. Analogamente, uma semente pode estar direcionada a um solo que não existe ou que ela nunca vai encontrar e um sal pode ser solúvel mesmo em um ambiente sem nenhuma água.

c) Direcionalidade a protótipos. Algo pode intencionar um tipo em vez de um objeto. Assim, desejamos água e não um copo d'água em particular. Analogamente, um sal se dissolve em qualquer água, um carrapato suga o sangue de qualquer mamífero, uma semente germina em qualquer terra fértil.

d) Opacidade e sensibilidade a modos de apresentação. O elo intencional é sensível ao modo como o objeto intencionado se apresenta. Essa característica parece marcar a intencionalidade mental: sabemos coisas sobre Clark Kent ou a estrela da manhã que não sabemos sobre o Super-Homem ou a estrela da tarde. Analogamente, um sal não se dissolve em água congelada e um carrapato não ataca um mamífero que está vestindo uma armadura.

Assim, Molnar aponta para disposições como propriedades intencionais direcionadas a coisas que não necessariamente existem (b acima), que podem ser protótipos satisfeitos por mais de um item particular (c acima) e que estão condicionados a um modo de apresentação (d acima). Com Molnar, podemos entender que certas partes do mundo estão dispostas a alguma coisa, como o carrapato está disposto a se alimentar de um mamífero.

Disposições carregam ao seu redor cenários que podem ser condensados em condições ceteris paribus. Estar disposto é já pressupor essas condições e atuar como um dispositivo ceteris paribus (que chamaremos de DCP), um dispositivo de introdução (ou pressuposição) de um ambiente fixo. Um DCP se direciona a protótipos e age em relação a eles. Muitas partes do mundo são DCPs, não apenas mentes humanas, mas também carrapatos, abelhas e sais. Não há um elo entre um sal e uma porção de água em particular, mas apenas entre o sal e o protótipo água. DCPs tratam as demais coisas segundo protótipos e, assim, inauguram perspectivas. O carrapato trata como indiferenciado (para ele) qualquer mamífero e distingue entre regiões do corpo do mamífero que são indiferentes para a pulga. Uma perspectiva é uma matriz de diferenças e indiferenças. ${ }^{12} \mathrm{DCPs}$, introduzindo protótipos, introduzem essas matrizes. ${ }^{13}$ Disposições, enquanto personagens de

12 Podemos pensar em termos de perspectivas temporais, como consideramos na seção passada. Por exemplo, a perspectiva do tempo atual, o presente no século XXI. Os séculos XX e XXII se diferenciam (passado e futuro) enquanto os séculos passados ficam indiferenciados (enquanto passado).

13 A noção de DCP pode ser comparada com as noções de caixa-preta e de ação a distância de Latour (1987). Os protótipos permitem que as disposições apontem para universais como água, mamífero 
uma ontologia, produzem e habitam regimes de sensibilidade que não podem ser descritos por uma metafísica de paisagem.

\section{Perspectivas no mundo}

TMT pode parecer incitar alguma forma de relativismo, seja individual ou cultural, uma vez que instaura uma ontologia aberta, sujeita a reinvenções, relativa a indexações, onde o que há está em uma trama. Parte do incômodo que emerge é dissipada se considerarmos o caráter ontológico do relativo - ele não é uma dimensão da nossa maneira (insuficiente) de contemplar o mundo, mas é antes uma dimensão do mundo. O mundo é, ele mesmo, fragmentado. As teorias que fazemos sobre o mundo são parte deste mundo e por isso são relativas ao que as circunda. Teorias são produtos de alianças que se provaram resilientes entre todo tipo de elementos do mundo. $\mathrm{O}$ caráter ontológico do relativo pode ser expresso assim: teorias não são torres de controle que permitem vistoriar o que há como uma paisagem; elas são outros elementos que são compreendidas apenas desde perspectivas e apenas compostas com outras coisas afetam a trama das coisas.

O caráter ontológico do relativo está associado à rejeição da ideia de que há uma perspectiva privilegiada - a rejeição das diversas formas de A-ismo não-neutro. Tudo é relativo a alguma coisa, a alguma medida, se quisermos, e não há nenhuma medida que pode ser tomada sempre e para todas as coisas. Perspectivas não estão prontas - elas são tramadas.

Aqui estamos também na vizinhança do trabalho de antropólogos como Tânia Stolze Lima (2005) e Viveiros de Castro (2009) sobre o multinaturalismo perspectivista ameríndio. Viveiros de Castro contrasta o mononaturalismo europeu - associado ao multiculturalismo - com o multinaturalismo dos nativos do baixo Amazonas. Ele considera que o trabalho antropológico é uma espécie de ontografia comparada e enxerga com bons olhos a adoção de um multinaturalismo. Segundo o mononaturalismo, há uma realidade de fundo, uma unter-realidade, que poderia em princípio ser acessível como uma paisagem vista por alguém ainda que invisível para nós. Há várias maneiras de ver e se relacionar com uma natureza - as relações são de alguma maneira posteriores a ela e as coisas são de uma maneira ou de outra independentes da relação que estabelecemos com elas. É como se a relações não fossem

ou polinizador. Latour, no entanto, abraça um atualismo motivado por um temor ao compromisso com essencialismos. Com isso, ele joga fora as disposições junto com as essências. Cf . Graham Harman (2009) para uma apresentação sistemática dos elementos da metafísica de Latour. 
constitutivas, apenas elementos acidentais acoplados aos elementos naturais. É do mononaturalismo que surge a ideia de que algumas coisas (indexações, disposições, conexões etc.) são uma segunda criação a partir do ponto de partida do que veio pronto, de uma base, de uma paisagem primordial. $\mathrm{O}$ multinaturalismo, por outro lado, elimina essa realidade de fundo e a substitui por uma ontologia do relacional com espaço para o que é indexical - todos os substantivos são tratados como demonstrativos - e para a multiplicidade de perspectivas que não compartilham nada em principio e que podem se multiplicar, se reagrupar e se recompor. As perspectivas são partes do mundo. O multinaturalismo permite uma comparação entre perspectivas que não envolve a busca de um máximo fator comum (onde o mononaturalismo procura o natural comum às diversidades de perspectiva), mas antes uma aproximação do que são duas coisas em perspectivas diferentes. No exemplo de Viveiros de Castro, o sangue é para a onça o que o cauim (cerveja de mandioca) é para os humanos - só se traduzimos sangue por cauim começamos a poder entender a perspectiva da onça. Não há substrato comum entre o sangue-para-humanos e o cauim-para-a-onça, há antes um elemento abstrato comum entendido como aquilo com que nos relacionamos como sendo cauim. Nada é substancialmente nada, e todas as coisas estão em relação com outras - essas relações, que constituem protótipos, estão presentes em todos os âmbitos do universo.

Há aqui um contraste importante entre a metafísica de paisagem e a metafísica de tramas. Paisagens estão associadas à ideia de que os componentes do mundo satisfazem um padrão de identidade universal. A metafísica de paisagem comumente endossa algum critério de existência para estabelecer que classe de entes constituirá a ontologia, ou seja, que condições um objeto deve satisfazer para que seja considerado real (por exemplo, ser material). Um critério que estabelece condições necessárias e suficientes de existência decide a priori como serão tratados os objetos em casos limítrofes (como objetos intencionais, abstratos e fictícios) e serve, deste modo, como condição de possibilidade para um princípio universal de extensionalidade. E princípios de extensionalidade, por sua vez, que funcionam como um método para se determinar o sentido de nossos termos, em geral têm de supor já estabelecidas, segundo um padrão comum, as identidades dos entes que servirão como extensões. A identidade está vinculada a um padrão de discernibilidade universal. Em contraste, uma metafísica de tramas aponta em favor de uma ontologia em que coabitam diferentes padrões de extensionalidade. ${ }^{14}$ 
Pensamos que o plano de imanência é um campo pré-extensional. Cada perspectiva (cada relato ontológico ou descrição completa do mundo) é a aplicação de um DCP sobre a composição do plano de imanência, criando condições extensionais para que opere algum tipo de princípio de substituição e se possa falar em uma única ontologia. Ou seja, chamamos de perspectiva a fixação de uma paisagem ontológica, isto é, um ambiente extensional. Nenhum objeto coexiste em mais de uma perspectiva do mesmo modo. É certo que podemos falar, dentro de cada perspectiva, de indiscernibilidade dos idênticos e, portanto, de itens que tem sua identidade preservada através de mundos possíveis. Mas a extensionalidade requer objetos cuja identidade é decidida sob um ponto de vista de parte alguma. A marca da metafísica de paisagens é o fascínio pelos objetos e por critérios não-relacionais de identidade. A metafísica de tramas, em contraste, é uma espécie de multipaisagismo, em que as paisagens são sempre relativas a alguma perspectiva. Em uma ontologia de protótipos, as relações precedem qualquer objeto. A trama consiste em que é somente dentro de uma perspectiva que os objetos transitam com uma mesma identidade, sendo que perspectivas são, elas mesmas, arranjos de estados intencionais.

A metafísica de tramas não é uma metafísica instaurada por algum princípio de extensionalidade: cada perspectiva é um ponto de vista sobre a imanência indexado dentro da própria imanência. Não há perspectiva de parte alguma pois toda perspectiva é a implementação de um plano de transcendência sobre e desde a o plano dos acontecimentos. A imanência é pois um plano de opacidades referenciais em que as perspectivas se relacionam produzindo e desmantelando ambientes de protótipos. Não é um plano de objetos, mas um plano de confluências. E é nas confluências que têm lugar as tramas. As perspectivas indexam elementos dentro de outras perspectivas e na própria imanência. Elas são o ponto de partida das tramas, o conflito entre pontos de vista, entre as relações que compõem aquilo que há.

\section{Em direção a um an-arché-ismo ontológico}

A metafísica de tramas pretende oferecer uma alternativa ao dilema entre os problemas da metafísica de paisagens e as dificuldades do abandono de

\footnotetext{
de que a realidade não possui camadas, e suficientemente rica, de modo a garantir a aplicabilidade de nossos predicados ordinários em geral. A ideia de níveis de realidade provem da intuição de que as predicações de pelo menos algumas ciências especiais têm de encontrar propriedades hieraquicamente equivalentes no mundo (uma vez descartadas as hipóteses reducionistas e eliminativistas). Em um espírito próximo à metafísica de tramas, Heil recusa o princípio, muitas vezes implícito, de que nossos predicados se aplicam isolando propriedades fixas no mundo.
} 
qualquer pretensão metafísica. Neste trabalho procuramos não mais do que esboçar o que seriam metafísicas de tramas e traçar em linhas gerais alguns elementos de uma metafísica assim que congrega três realismos: acerca das indexicalidades, acerca das disposições e, em consequência, acerca das perspectivas. Essa metafísica, como dissemos, é uma dentre as que podem ser encorajadas por TMT. Tal tese aponta em direção a uma imagem do mundo onde não há uma arché, mas antes uma confluência de projetos (que podem ser pensados em termos de perspectivas, posições e disposições) que partilham de um espaço comum. Se estamos certos quanto à pertinência de TMT, a metafísica pode deixar de ser uma atividade totalizante e passar a ser uma atividade de composição com os elementos diversos que constituem a realidade.

\section{Referências bibliográficas}

BERGSON, H. (1907/2007) L'evolution créatice. Paris: Presses Universitaires de France.

CANTWELL SMITH, B. (1996) On the origin of objects. Cambridge, Massachusetts: The MIT Press.

DELEUZE, G \& GUATTARI, F. (1980/2007) Mille Plateaux, Paris: Les Éditions de Minuit, 1980. Edição Brasileira: Mil Platôs, São Paulo: Editora 34.

ELLIS, B. (2002) The Philosophy of Nature: A guide to the new essentialism. Canada: McGill-Queen's University Press.

FINE, K. (2005) Tense and reality, in: Modality and tense: Philosophical papers. Nova Iorque: Oxford University Press, pp. 261-320

HARMAN, G (2009) Prince of Networks: Bruno Latour and Metaphysics. Prahran, Victoria: re.press.

HEIL, J.; MARTIN, C. B. (1999) The Ontological Turn. Midwest Studies In Philosophy. v. 23, n. 1, p. 34-60.

HEIL, J (2003). From an ontological point of view. Nova Iorque: Oxford University Press.

LATOUR, B. (1987) Science In Action: How to Follow Scientists and Engineers Through Society. Cambridge, Massachusetts: Harvard University Press.

LEWIS, D. (1986) On the plurality of worlds. Padstow, Cornwall: Blackwell Publishing.

LIMA, T. S. (2005) Um Peixe Olhou Para Mim: O povo Yudjá e a perspectiva. São Paulo: UNESP/ ISA/ NUTI.

MCTAGGART, J. (1908) The unreality of time. Mind. n. 17, p. 457-73. MARTIN, C. B. (1994) Dispositions and Conditionals. Philosophical Quarterly. v. 44, n. 174, p. 1-8. 
MCDOWELL, J. (1994) Mind and World. Cambridge, Massachusetts: Harvard University Press.

HARR, M. (1993) Nietzsche et la métaphysique. Paris: Gallimard.

MOLNAR, G. (2003) Powers: a study in metaphysics. Editado por Stephen Mumford. Nova Iorque: Oxford University Press.

MUMFORD, S. (1998) Dispositions. Nova Iorque: Oxford University Press. . (2004) Laws in nature. Londres: Routledge.

NAGEL, Th. (1989) A view from nowhere. Nova Iorque: Oxford University Press.

NIETZSCHE, F. (1886) Humano Demasiado Humano II, parte 2, seção 61. Companhia das Letras, 2008.

PRIOR, A. N. (1968) Papers on Time and Tense. Nova Iorque: Oxford University Press.

SOURIAU, É. (1943/2009) Les différents modes d'existence. Paris: Presses Universitaires de France.

UEXKÜLL, J. \& KRISZAT, G. (1934). A Stroll through the Worlds of Animals and Men. In: Clair Schiller (ed), Instinctive Behavior, 1957. Nova Iorque International Universities Press.

VIVEIROS DE CASTRO, E. (2009) Métaphysiques cannibales: lignes d'anthropologie post-structurale. Paris: Presses Universitaires de France.

WHITEHEAD, A. N. (1929) Process and Reality. Nova Iorque: The Free Press. 